\title{
História e legitimação organizacional: reflexões acerca das narrativas histórico-organizacionais
}

History and organizational legitimacy:

reflections on the organizational-historical narratives

Historia y legitimidad organizacional:

reflexiones sobre las narrativas histórico-organizacionales

Larissa Conceição dos Santos

- Doutoranda em Sciences de l'Information et de la Communication na Université Paris-Sorbonne (Paris IV)

- Mestre em Sciences de l'Information et de la Communication pela Université Paris-Sorbonne (Paris IV)

- Mestre em Engenharia da Produção pela Universidade Federal de Santa Maria (UFSM)

- Bacharel em Administração e bacharel em Comunicação Social - Relações Públicas pela UFSM

- Bolsista Capes de Doutorado Pleno no Exterior

- Pesquisadora no Groupe de Recherches Interdisciplinaires sur les Processus d'Information et de Communication (Gripic), Celsa, Université Paris-Sorbonne

- E-mail: Larissa.conceicao_dos_santos@celsa.paris-sorbonne.fr 


\section{Resumo}

A história se (re)constrói também no presente, através das rememorações, narrações e reconstituições mnemônicas. Neste estudo, analisa-se o lugar da história nas organizações e sua interface com a comunicação organizacional, destacando 0 papel das narrativas para a sua legitimação. Observa-se a construção das narrativas histórico-organizacionais como uma estratégia legitimante que busca dar coerência à atividade organizacional e ressaltar sua função social.

\section{PALVRAS-CHAVE: COMUNICAÇÃO ORGANIZACIONAL・NARRATIVAS・HISTÓRIA•MEMÓRIA.}

\section{Abstract}

History is also (re)constructed currently through the rememorations, narrations, and mnemonic reenactments. In this article we analyze the place of history in organizations and its interface with organizational communication, highlighting the role of narratives for their legitimation. The construction of the organizational-historical narratives is observed as a strategy that legitimately seeks to provide coherence to the organizational activity and highlight its social function.

KEYEWORDS: ORGANIZATIONAL COMMUNICATION •NARRATIVES・HISTORY・MEMORY.

\section{Resumen}

La historia se (re)construye también en el presente, a través de rememoraciones, narraciones y reconstituciones mnemónicas. En este artículo se analiza el lugar de la historia en las organizaciones y su interfaz con la comunicación organizacional, destacando el papel de las narrativas para su legitimación. Se observa la construcción de las narrativas histórico-organizacionales como una estrategia que legitima la búsqueda por dar coherencia a la actividad organizacional y resaltar su función social. 
A sociedade observada através do paradigma pós-moderno (Lyotard, 1979; Harvey, 1990) revela características peculiares que influem no comportamento humano, bem como nas decisões políticas e organizacionais. Diante da crise das metanarrativas explicativas e totalizadoras, os indivíduos encontram-se em um período de busca de um sentido identitário, de referências e de valores a serem seguidos.

Nesse cenário emergem na sociedade diferentes discursos (políticos, midiáticos, religiosos) buscando atrair a atenção dos públicos e propor novas "verdades" ou mesmo diretrizes balizadoras. Tal abertura propicia o surgimento das narrativas organizacionais, as quais encontram espaço e audiência, tendo a história da empresa como temática e fonte legitimante.

A narrativa da história organizacional permite humanizar a empresa, destacar sua trajetória e ao mesmo tempo exaltar aqueles que ajudaram a construí-la. Da mesma forma, ao narrar a história, evidenciam-se suas raízes e seus princípios, atribuise uma identidade e uma singularidade à organização com as quais os diferentes públicos podem, por sua vez, identificar-se.

Como um fio condutor ligando passado, presente e o futuro, a narração histórico-organizacional permite dar coerência às ações da empresa em uma perspectiva temporal. Mais que uma fonte de unicidade, a história e a memória organizacionais constituem-se como verdadeiros elementos de legitimação organizacional.

Ao narrar sua história, a organização não apenas recupera seu legado, mas coloca em evidência e legitima discursivamente seus feitos, seus atos, suas decisões, reforçando sua existência por meio de uma comunicação afirmativa que ressalta sua função social.

Assim, a construção histórico-narrativa nas organizações contemporâneas ultrapassa a celebração mítica e as produções hagiográficas e dá lugar a uma narrativa pautada pelo real e - por que não dizer? - pelo presente. 0 culto aos personagens fundadores é substituído pelo aporte histórico nacional, onde a organização se vê partícipe no desenvolvimento da sociedade e da nação. Essa dinâmica histórico-narrativa pode ser observada, ainda, como um processo de construção simbólica da memória econômica e industrial do país.

Nesse sentido, pretende-se, através deste ensaio, observar o papel da história nas organizações e sua interface com a comunicação organizacional, ressaltando a produção das chamadas narrativas histórico-organizacionais. A relação entre as narrativas construídas pelas empresas e as alterações no regime temporal, impostas na sociedade, também são objetos de reflexão, para os quais encontra-se resposta na evocação da história organizacional.

\section{A HISTÓRIA NASORGANIZAÇÕES OU A HISTÓRIA DASORGANIZAÇÕES?}

A história organizacional pode ser considerada uma temática de estudos relativamente recente. A chamada business history começava a florescer nos Estados Unidos já em meados de 1927 e, posteriormente, na Inglaterra nos anos 1950. Mas é apenas na década de 1970 que o campo de estudos comumente denominado história de empresas, começa a fortalecer-se na França e no Brasil (Freitas Filho, 1989). 
Com relação ao conceito de história organizacional, é preciso salientar a existência de diferentes acepções e definições, influenciadas, sobretudo, pelas distintas perspectivas de estudo dessa área (corrente gerencial, ligada à business history, corrente histórica francesa influenciada pela École de Annales, corrente economicista, ligada aos estudos de história econômica, corrente sociológica, entre outras).

De acordo com o historiador François Caron (1987, p. 9), a história organizacional pode ser definida como

a resultante de um processo de aprendizagem coletiva, ou mais bem a combinação de uma série de processos desse tipo. Eles formam os componentes de uma cultura de empresa, cuja definição pode ser apreendida de uma maneira real apenas pela base de uma história cientificamente conduzida.'

Félix Torres (1987), historiador e especialista em história e memória de empresas, salienta as diferenças existentes entre 0 conceito de história nas organizações, que remete à história no seio das empresas (construída, mas que também circula no interior delas) e história das organizações, referindo-se à história-relato, monográfica, associada ao mundo acadêmico, a qual visa retraçar a trajetória da empresa de forma retrospectiva.

Como historiador e doutor em informação e comunicação, Julien Tassel (2008) distingue duas abordagens históricas: de um lado a perspectiva acadêmica, dita tradicional, conduzida pelos historiadores, e de outro a história produzida nas empresas, história gerencial, realizada pelos gestores. Segundo ele, estas são duas expressões da história; no entanto, uma não existe sem a outra.

Para além da definição teórica, imprescindível à compreensão do sujeito, destaca-se, igualmente, o seu desenvolvimento prático, sua construção empírica, resultante do encontro entre a empresa e a história, e, inicialmente, entre o gestor e o historiador.

Apesar do desinteresse inicial e recíproco entre historiadores e empresários, atualmente a história organizacional vem ganhando espaço e reconhecimento tanto no âmbito acadêmico quanto no profissional. Os historiadores, que outrora a observavam com receio, são hoje os principais protagonistas na sua construção, atores legitimados pelas próprias organizações as quais thes outorgam, muitas vezes, a responsabilidade pelas atividades histórico-organizacionais.

No entanto, para que o diálogo entre história e empresa fosse estabelecido, fez-se necessária, primeiramente, uma mudança de mentalidade de ambas as partes. As organizações abriram suas portas às pesquisas e aos pesquisadores, e, sobretudo, à integração dos estudos em ciências sociais e humanas (pós- escola das relações humanas). Os historiadores, por outro lado, superaram o receio e começaram a ver na história uma importante ferramenta para a compreensão da identidade e cultura empresariais, e para o estudo da evolução das organizações e do desenvolvimento das sociedades.

As diferenças e o distanciamento inicial entre empresa e história são também de base conceitual. A palavra empresa originase do verbo empreender, agir sobre o presente, alterá-lo, projetá-lo no futuro, enquanto o fazer histórico esteve, na visão dos empresários e gestores, durante muito tempo associado a passado. Estes últimos viam nas abordagens historiográficas uma forma de retrocesso, um obstáculo ao progresso, remetendo ao tradicional ou ainda ao obsoleto, culminando na negação do passado. Já os historiadores acadêmicos eram considerados uma ameaça, pois poderiam trazer à luz os segredos, as falhas e omissões das organizações. 
Para superar essa aversão ao passado, as empresas precisaram passar por um período de reavaliação. Diante de tantas incertezas, em um mundo em constante mutação, a organização começa a questionar-se sobre sua própria essência e, como consequência, volta-se à sua história. 0 olhar ao passado simboliza, então, a busca da identidade, dos valores, da cultura e das raízes da organização, pois, "face à série de fatores bastante complexos que orientam e condicionam o futuro, doravante o recurso à história não parece nem supérfluo, nem sinônimo de passadismo e de estagnação"2 (Torres, 1987, p. 28).

Empresas eempresárioscomeçaramaentenderque oreconhecimento dahistória passava também por umautoconhecimento do fazer organizacional, da razão de ser das organizações, da missão e dos propósitos pelos quais ela fora norteada desde sua fundação. Tal reflexão resulta fundamental a fim de que as organizações possam assumir seus papéis na sociedade. Uma responsabilidade pública que implica a valorização da história organizacional.

Essa nova relação entre história e empresa, calcada pelo reconhecimento da história organizacional, foi impulsionada, igualmente, pelo esclarecimento da conexão entre passado e presente. Muitas vezes colocados em oposição, estes conceitos estariam conjugados, como um estado atual e outro retrospectivo (Torres, 1987). 0 presente é o passado refletido, de onde a importância da trajetória empresarial, fonte de compreensão, de previsão e de legitimação para as organizações.

Como resultantes do processo de valorização da história organizacional observa-se atualmente a existência de associações, comitês, centros de história/memória ou ainda o desenvolvimento de projetos desse âmbito no interior das empresas. A história é assim observada como um produto, resultado do processo de produção, do trabalho desenvolvido pelos comitês e centros de história/memória, bem como pelos departamentos de comunicação.

Sob essa ótica analisa-se a história como uma atividade que provém da ação. Ou seja, ela não é fixa, estática ou dada, mas sim elaborada. Em outras palavras, a história entendida como um "fazer", fruto do trabalho e esforço para construí-la, "é uma operação localizada em um determinado espaço e tempo dados, resultante de procedimentos precisos e de uma escrita específica" (Tassel, 2008, p. 48³).

Tal visão remonta à hipótese de um processo de construção narrativa por trás dos projetos histórico-organizacionais, o qual encontra na comunicação organizacional o mecanismo de difusão e midiatização da história. Nesse processo de comunicação histórico-narrativo, cabe à organização selecionar os elementos que ela deseja mostrar e a maneira pela qual ela quer ver contada a sua história.

A evocação do passado nas narrativas organizacionais visa demonstrar a continuidade de uma organização. Uma forma de reiteração do passado ou das marcas do passado na atualidade. Narrar a história de uma empresa, comunicar seus feitos aos públicos mais diversos constitui uma forma de legitimar o percurso de uma empresa como duradoura, sólida, perene.

\section{HISTÓRIA, TEMPORALIDADE E POLIFONIA NARRATIVA}

0 apelo à história e o exame do passado levam à compreensão do presente, em um enfoque retrospectivo, mas também à antecipação (e preparação) do futuro, em uma abordagem prospectiva. Dessa forma, a história organizacional torna-se 
fonte e objeto das narrativas construídas pelas organizações. 0 conceito de narrativas histórico-organizacionais está relacionado à problemática da temporalidade nas organizações, construído na interface entre a história/memória, a narrativa e o tempo.

Elizabeth Gardere (2003) destaca a existência de um laço metodológico que une a narrativa e a história. Nessa relação poderíamos inferir que a história remete ao objeto científico, resultado de pesquisas teóricas e metodológicas validadas cientificamente, enquanto a narrativa representa a sua restituição, o objeto concreto, fonte para a construção e recuperação da memória organizacional e a análise do passado e presente da organização.

Da mesma forma, uma relação de complementaridade se estabelece entre a narrativa e a memória. É através das narrativas que a memória se forma, se (re)constitui e circula nas organizações (Gardere, 2003).

Se podemos assim ler as histórias que a humanidade se conta a si mesma como o fluxo constitutivo da memória e, portanto, de sua identidade, nem por isso o próprio movimento da narração deixa de ser atravessado, de maneira geralmente mais subterrânea, pelo refluxo do esquecimento; esquecimento que seria não sô uma falha, um "branco" de memória, mas também uma atividade que se apaga, renuncia recorta, opõe ao infinito da memória a finitude necessária da morte e a inscreve no âmago da narração (Gagnebin, 2011, p. 3).

É na dialética do lembrar e esquecer e na tessitura da narrativa que a história organizacional é cuidadosamente (re)construída. O esquecimento, pontuado por Gagnebin (2011), não apenas é inevitável como também necessário à sobrevivência da memória. A maneira como a história é evocada e, consequentemente, relatada, denota uma escolha estratégica (entre o lembrado e 0 esquecido), mas também uma temporalidade particular ao processo de construção narrativa e de restituição histórica.

Destaca-se, nesse sentido a relação entre tempo e narrativa. Segundo Paul Ricoeur (2011), "é a narrativa que torna acessível a experiência humana do tempo, o tempo só se torna humano através da narrativa". Para o autor, a inteligibilidade da narrativa reside no reconhecimento de seu papel mediador, atuando como um divisor de águas entre dois momentos distintos, um ponto inicial (no tempo) e um ponto final.

Assumindo-se que o presente não possui extensão, a legitimidade do passado e do futuro se configura através da narrativa. A narrativa do passado é composta por memórias, vestígios das "imagens do passado" fixadas em nossa mente, às quais atribuímos um sentido de "real" ou verdadeiro. A narrativa do futuro está relacionada à previsão, à antecipação dos acontecimentos, pressupondo uma expectativa (Ricoeur, 2011).

As implicações de tais práticas temporais na empresa podem ser observadas através das diferentes percepções da história organizacional, segundo seus públicos. A história pode ser percebida de maneira diferente pelos funcionários em relação àquela observada pelos gestores. Para Tassel (2008), esse fenômeno caracteriza uma forma de gestão simbólica das representações temporais, ilustrada pela diferença entre o horizonte de expectativa dos gestores e a experiência vivida pelos funcionários.

Diferentes vozes dentro da organização relatam suas experiências e sua versão da história organizacional. Torna-se imperativo conhecer e reconhecer essa polifonia, melhorar e incorporar essas experiências no processo de narração da história organizacional, destacando a pluralidade de vozes que compõem a organização.

O contraste entre a visão dos gestores e a visão dos colaboradores pode, muitas vezes, suscitar diferentes versões da história organizacional ou, ainda, gerar incerteza e insegurança entre os funcionários face ao desconhecido, ao novo. Com 
a mudança há, portanto, uma espécie de perda de evidência na articulação entre as dimensões temporais do passado, presente e futuro (Tassel, 2008, p. 331).

Segundo Tassel (2008), as organizações utilizam técnicas de "enquadramento" como forma de atualizar as representações ou dar um novo significado às ações estratégicas. Os valores atuais, de pertença ao passado e ao presente são, então, propostos e reatualizados pelos gestores por meio de quadros de reinterpretação. 0 autor identifica a existência de duas estratégias nas empresas, relacionadas à temporalidade: uma lógica de continuidade e outra de descontinuidade temporal.

A lógica de descontinuidade temporal apresenta a mudança a partir de uma leitura da atualidade. Por outro lado, a lógica de continuidade se refere ao passado e relativiza a mudança (a mudança é vista como um ciclo no qual a empresa atravessa de tempo em tempo). Os gestores recorrem à narrativa da história para reforçar e naturalizar a mudança, apresentando-a como um evento inevitável, que faz parte da trajetória da empresa.

A narrativa e a história são colocadas ao serviço do gerenciamento, pois ele permite ilustrar a ideia segundo a qual a empresa, para chegar onde ela está, soube atravessar um certo número de mudança, se adaptar as conjunturas, encontrar os meios de sua perenidade (TasseL, 2008, p. 3434).

Para Loiseau (1987), a história é entendida como uma "constatação", isto é, o reconhecimento da inserção dos processos de comunicação no tempo. Pode-se identificar, nesse sentido, duas temporalidades: uma ligada ao acontecimento original (servindo de objeto à comunicação) e outra relacionada ao momento em que a comunicação é produzida, onde a história é convocada.

A segunda temporalidade associa-se àquela da produção narrativa. Remete a elaboração e consequente narração da história organizacional, por meio da qual a empresa se esforça em conectar seus valores originais, suas raízes às práticas atuais, como forma de demonstrar a continuidade entre passado e presente e a perenidade organizacional. A história é contada de diferentes maneiras, no intuito de destacar a origem e continuidade da identidade, apesar de todas as mudanças sofridas pela empresa.

0 recurso à narrativa da história organizacional responde também a uma lógica de aceleração do tempo (Rosa, 2013) imposta à sociedade. Presencia-se atualmente uma alteração da ordem temporal, impulsionada pela velocidade da informação, das mutações sociais, políticas e econômicas. Diante desse desafio, as organizações buscam configurar seus discursos de maneira a apresentar uma história perene e coerente ao longo dos anos, mas também, e principalmente, torná-la visível e acessível aos diferentes públicos.

Da mesma forma, conforme destaca Suzana Ribeiro (2013), essa nova lógica temporal (acelerada, descontínua e dinâmica) outorga à história escrita uma função de atribuição de sentidos e de pertencimento. A perda de certas referências, 0 esquecimento, a desvalorização de arquivos, dos sujeitos e elementos portadores da memória social e institucional tornam o processo de escrita histórica o "resultado de um trabalho de seleção documental e análise dos historiadores de um tempo, em que se pode ou não dizer ou registrar fatos e eventos" (Ribeiro, 2013, p. 17).

A disponibilização da história organizacional através dos sites empresariais denota uma preocupação relativa à preservação do passado e também um desejo de "patrimonialização". Os processos de arquivamento e salvaguarda de informações e

$\overline{4 \text { Tradução nossa. }}$ 
dados históricos, possibilitados pelos meios eletrônicos e digitais, atualizam o passado ou o resgatam, eternizando-0 no presente graças a uma disponibilização instantânea (Pignier, 2010), bem como a favorecem o registro online, 0 compartilhamento e a troca de experiências entre os indivíduos, em um anseio de preservação para o futuro de uma memória dita virtual (Dodebei; Henriques; Werneck, 2013).

Esse processo de midiatização da história não apenas resgata o passado da organização, proporcionando visibilidade às suas ações e possibilitando o registro histórico relacionado a um segmento industrial ou corporação específica, mas também constitui uma estratégia de legitimação organizacional.

\section{A LEGITIMAÇÃO PELA HISTÓRIA}

A desconfiança para com as abordagens historiográficas é superada quando as empresas começam a servir-se da história para legitimar-se.

Para Bonin (2006), 0 apelo à história organizacional denota uma forma de "instrumentalização valorizante". 0 autor observa as mutações econômicas ocorridas durante o período da Grande Crise na França, entre 1970 e 1990, as quais tornaram 0 cenário propício ao desenvolvimento da história organizacional e contribuíram para sua instrumentalização, chamada a participar em uma missão de legitimação da empresa.

Em cenários de crise as organizações veem seus sistemas fragilizados, sua capacidade a afrontar os obstáculos e a concorrência também é interpelada. Face ao questionamento de seus valores e de sua utilidade as organizações podem padecer de uma "crise de legitimidade". Nesse contexto, de acordo com o autor, a história seria convocada pelas empresas como forma de encarar e superar os períodos de instabilidade econômica e financeira aos quais estariam sujeitas.

$\mathrm{Na}$ perspectiva de Hubert Bonin (2006) a história é igualmente resgatada e relatada a fim de mostrar a coerência organizacional. 0 percurso detalhado da organização serviria à legitimação de seus feitos e da importância de sua existência.

As estratégias de legitimação organizacional também foram investigadas por Tereza Lúcia Halliday (1987; 2009). A partir de um estudo comparativo, analisando as práticas de autodescrição de multinacionais francesas, brasileiras e norte-americanas, a autora conclui que as organizações buscam legitimar-se através da retórica ou da construção retórica de seus discursos.

A "crise de legitimidade", salientada por Bonin (2006), é destacada por Halliday (1987) através da "legitimidade questionada" sofrida empresas multinacionais. Isto é, as variáveis em torno de sua atuação, sobretudo no que tange às formas de poder exercidas por empresas multinacionais, tornam questionável a sua legitimidade. A solução é buscada por meio da construção simbólica da realidade, operada através de trocas com o meio (Halliday, 1987).

A autora identifica alguns temas recorrentes nos discursos organizacionais, os quais denomina "temas legitimadores". Tais argumentos evocam qualificações e virtudes, como a excelência e utilidade organizacionais, a identificação com os interesses e as necessidades dos públicos, bem como a transcendência (Halliday, 2009). 
Observa-se esse tipo de apelação através das produções histórico-narrativas, onde a história organizacional é narrada como atuante e participativa na construção da história nacional. Essa visão é incorporada aos livros empresarias e aos discursos dos dirigentes, onde, através da evocação da história organizacional, se busca ressaltar a função social da empresa e seu aporte à sociedade.

Além disso, as narrativas histórico-organizacionais podem servir à justificação das ações da empresa em um contexto histórico especifico. Recuperar e contar a história organizacional, nesse sentido, permite legitimar as decisões estratégicas das empresas, justificando as escolhas em função das exigências do período em que foram tomadas.

Identifica-se, nessas práticas, a convergência da história ao serviço de uma lógica de promoção do patrimônio econômico nacional (regional, setorial etc.), onde a narrativa da história organizacional é instrumento fundamental de promoção institucional, mas também de legitimação política e ideológica (Bonin, 2006).

Assim, através das narrativas as empresas buscam validar a sua existência, mostrando suas prestações à sociedade (função social), bem como reforçam sua capacidade de adaptação ao meio e adequação entre os objetivos e valores organizacionais e aqueles dos públicos aos quais se destinam.

Reduzir o hiato existente entrea "percepção pública" (a maneira pela qual a empresaé percebida pela sociedade) ea "percepção idealizada" (a maneira pela qual ela gostaria de ser percebida) constitui o principal problema retórico das empresas.

Sofrendo de legitimidade questionada, as multinacionais procuram resolver seu problema retórico desenvolvendo um discurso legitimizante em torno de tópicos capazes de credenciá-las como persona grata. (...) as multinacionais apelam para o nosso interesse em obter benefícios, as nossas necessidades de segurança, as nossas preocupações humanistas e o nosso orgulho nacional (Halliday, 1987, p. 19).

Bonin (2006) avalia essas medidas como estratégias de legitimação política, visando restabelecer a confiança do público interno e promover a empresa perante a opinião pública. 0 autor salienta a existência de um movimento interno, que usa a história para dar um sentido à atividade empresarial, incitando o culto à empresa. Para ele, as empresas buscam tirar proveito de seu passado e de seu percurso a fim de valorizar seu capital humano, suas origens, seus ativos imateriais.

A abordagem histórica também pode ser utilizada pelas organizações como complemento da política de comunicação. Internamente, a história organizacional funciona como um pilar, reforçando os valores de base, a identidade e cultura organizacional, os quais por sua vez serão refletidos à sociedade por meio da comunicação externa.

Tais práticas são observadas por Bonin (2006) como ações de comunicação institucional visando legitimar as empresas e torná-las atrativas econômica e financeiramente, diante de um mercado aberto, onde os acionistas procuram as companhias com maior potencial para efetuarem seus investimentos.

Segundo Loiseau (1987, p. 90), "a clareza de percepção de uma política de empresa requer que ela seja legível ao longo do tempo. É aí que a história - ou, em todo caso, uma certa história - cumpre um papel fundamental"5. A mobilização da história em benefício da comunicação publicitária e da imagem de marca são apenas alguns exemplos da aplicação histórica aos processos comunicacionais, pois "apresentar-se como carregada de história é o procedimento natural aos produtos que por 
natureza adquirem qualidade ao envelhecerem (...). A idade, que é a qualidade do produto, corresponde assim à antiguidade, que é aquela da marca" (Loiseau, 1987, p. 866).

A história ou a "historicidade" das empresas é reivindicada como um elemento de legitimação. Trata-se da valorização do tempo, do passado e da afiliação subentendida nessa relação temporal (reconhecimento das origens e dos fundadores). Uma empresa antiga e duradoura tem a destacar sua autenticidade perante as novas organizações, as quais muitas vezes não fazem mais do que imitar o passado.

Pode-se afirmar, com isso, que a história está associada à verdade, atribuindo um sentido de credibilidade e originalidade aos acontecimentos. No entanto, o resgate histórico só é possível através da memória e dos mecanismos ligados à ela: lembranças, relatos, objetos, arquivos. Observa-se a memória como uma (re)construção, um objeto da história e meio para a sua recuperação, acesso e interpretação.

Históriaememóriasão, portanto, analisadascomofontes delegitimaçãoorganizacional.Ambososcampossãocomplementares e sua relação complexa é explorada pela comunicação na composição das narrativas histórico-organizacionais.

\section{CONSIDERAÇÕES FINAIS}

Buscou-se nesse estudo ressaltar a abordagem histórica nas empresas, por meio das narrativas histórico-organizacionais. Observa-se a existência de processos comunicacionais desenvolvidos no intuito de narrar e de narrativizar a história organizacional com vistas à legitimação das empresas. A história, portanto, é objeto de uma construção narrativa, por meio da qual as organizações legitimam suas ações e reivindicam o seu papel na sociedade.

As organizações são parte constituinte da história de uma nação, elas integram e participam de sua formação. No entanto, através da produção de narrativas histórico-organizacionais, as empresas, muitas vezes, se apropriam da história em um processo de reinterpretação ou ressignificação.

A nova história, reatualizada e difundida por meio dos relatos organizacionais, afeta a percepção que os indivíduos possuem sobre os atores e os acontecimentos relatados. Essa rememoração forjada e adaptada aos interesses organizacionais participa, assim, da formação da memória social e da memória histórica e econômica de um país.

A dinâmica de releitura e reescrita da história se configura através de um processo comunicacional de construção (e difusão) de narrativas que descrevem a história da organização. Para tanto, distintos procedimentos são utilizados, tais como elaboração de narrativas interativas (cronológicas e enciclopédicas) via website da instituição, publicação de livros comemorativos (relatando a história organizacional), promoção de exposições (itinerantes, eventuais) e museus empresariais, entre outros.

Bonin (2006) critica, no entanto, a força de tais mensagens e sua capacidade de influenciar a percepção da opinião pública a respeito das organizações. 0 autor questiona a utilidade da narrativa da história, a qual, segundo ele, não aportaria uma reflexão profunda sobre a realidade das organizações, mas, sim, simbolizaria apenas um uso político e gerencial que visa reconstruir a legitimidade organizacional. 
Tais questionamentos e as críticas frequentemente atribuídas aos usos da história no contexto empresarial tomam em conta, muitas vezes, o recurso à hagiografia e à mitificação da história praticadas por algumas organizações.

Contra os abusos da memória, tais como as práticas de celebração ou culto ao passado, em detrimento do presente, defendese, conforme salienta Gagnebin (2006), um lembrar ativo, onde a rememoração possa ser usada em proveito do aprendizado, da compreensão e do esclarecimento do passado e do presente.

Dessa forma, também compete aos pesquisadores e profissionais de comunicação a análise crítica e o uso adequado das fontes históricas disponíveis, em prol de uma narração ética e transparente da história organizacional.

\section{REFERÊNCIAS}

BONIN, Hubert. L'histoire comme outil de légitimation politique de l'entreprise durant la Grande Crise de la fin du XXe siècle (1974-1993). In: CRIVELLO, Maryline; GARCIA, Patrick; OFFENSTADT, Nicolas. Concurrence des passés: usages politiques du passé dans la France contemporaine. Aix-en-Provence: PUP, 2006. p. 157-168.

CARON, François. Préface. In: HAMON, Maurice; TORRES, Félix (Org.). Mémoire d'avenir. Paris: Economica, 1987. p. 7-9.

DODEBEI, Vera; HENRIQUES, Rosali; WERNECK, Marcela. Evernote e Facebook aceleração tecnológica: arquivos eternos de memórias virtuais? Lumina, v. 7, n. 1, 2013.

FREITAS FILHO, Almir Pita. História econômica e história de empresa: algumas reflexões metodológicas. Ensaios FEE, v. 10 , n. 1, p. 168-177, 1989.

GAGNEBIN, Jeanne Marie. Lembrar, esquecer, escrever. São Paulo: Editora 34, 2006.

História e narração em Walter Benjamin. 2.ed., 4. reimpr.). São Paulo: Perspectiva, 2011.

GARDERE, Elizabeth. Le capital mémoire de l'entreprise. Paris: L'Harmattan, 2003.

HALLIDAY, Tereza Lúcia. A retórica das multinacionais: a legitimação das organizações pela palavra. São Paulo: Summus, 1987.

Discurso organizacional: uma abordagem retórica. In: Kunsch, Margarida M. Krohling (Org.). Comunicação organizacional. Vol 2. Linguagem, gestão e perspectivas. São Paulo: Saraiva, 2009.

HAMON, Maurice; TORRES, Félix. Mémoire d'avenir. l’histoire dans l'entreprise. Economica, 1987.

HARVEY, David. The condition of postmodernity. an enquiry into the conditions of cultural change. Oxford: Blackwell, 1990.

LOISEAU, Marc. Les modes de communication de l'histoire en entreprise. In: HAMON, Maurice; TORRES, Félix. Mémoire d'avenir. l'histoire dans l'entreprise. Economica, 1987. p. 81 - 91. 
LYOTARD Jean-François. La condition postmoderne. Paris: Minuit, 1979.

PIGNIER, Nicole. De l'internet à la mémoire humaine. Revue MEl, n. 32, p. 7-13, 2010.

RIBEIRO, Suzana, L. S. Memória institucional: o trabalho como elo de identidade e pertencimento. Revista Eletrônica de Tecnologia e Cultura, v. 1, p. 14-22, 2013.

RICOEUR, Paul. Tempo e narrativa I: a intriga e a narrativa histórica. [1983].São Paulo: Martins Fontes, 2011. 408 p.

ROSA, Hartmut. Accélération: une critique sociale du temps. Paris: La Découverte, 2013.

TASSEL, Julien. L'histoire saisie par le management: entre pratiques du passé et exercice du pouvoir managérial. 2008, 463 f. Thèse (Doctorat en Sciences de l'information et de la communication) - Celsa, Paris IV-Sorbonne, Paris, 2008.

TORRES, Félix. Retour vers l'avenir: l'histoire dans l'entreprise. In: HAMON, Maurice; TORRES, Félix. Mémoire d'avenir: l'histoire dans l'éntreprise. Economica, 1987. p. 21-42.

Artigo recebido em 11.03.2014 e aprovado em 24.06.2014. 